ARTICLE

Received 6 Mar 2014 | Accepted 29 Jul 2014 | Published 10 Sep $2014 \quad$ DOI: 10.1038/ncomms5840

\title{
Highly efficient inverted polymer light-emitting diodes using surface modifications of $\mathrm{ZnO}$ layer
}

Bo Ram Lee ${ }^{1}$, Eui Dae Jung ${ }^{1}$, Ji Sun Park², Yun Seok Nam, Sa Hoon Min³, Byeong-Su Kim³ ${ }^{3}$ Kyung-Min Lee ${ }^{4}$, Jong-Ryul Jeong ${ }^{4}$, Richard H. Friend ${ }^{5}$, Ji-Seon $\mathrm{Kim}^{6}$, Sang Ouk Kim ${ }^{7} \&$ Myoung Hoon Song ${ }^{1}$

Organic light-emitting diodes have been recently focused for flexible display and solid-state lighting applications and so much effort has been devoted to achieve highly efficient organic light-emitting diodes. Here, we improve the efficiency of inverted polymer light-emitting diodes by introducing a spontaneously formed ripple-shaped nanostructure of $\mathrm{ZnO}$ and applying an amine-based polar solvent treatment to the nanostructure of $\mathrm{ZnO}$. The nanostructure of the $\mathrm{ZnO}$ layer improves the extraction of the waveguide modes inside the device structure, and a 2-ME +EA interlayer enhances the electron injection and hole blocking in addition to reducing exciton quenching between the polar-solvent-treated $\mathrm{ZnO}$ and the emissive layer. Therefore, our optimized inverted polymer light-emitting diodes have a luminous efficiency of $61.6 \mathrm{~cd} \mathrm{~A}-1$ and an external quantum efficiency of $17.8 \%$, which are the highest efficiency values among polymer-based fluorescent light-emitting diodes that contain a single emissive layer.

\footnotetext{
${ }^{1}$ School of Materials Science and Engineering and KIST-UNIST Ulsan Center for Convergent Materials, Ulsan National Institute of Science and Technology (UNIST), UNIST-gil 50, Ulsan 689-798, Republic of Korea. ${ }^{2}$ Energy Nano Materials Research Center, Korea Electronics Technology Institute (KETI), 68 Yatap-dong, Bundang-gu, Seongnam-si, Gyeonggi-do 463-816, Republic of Korea. ${ }^{3}$ Department of Chemistry and Department of Energy Engineering, Ulsan National Institute of Science and Technology (UNIST), UNIST-gil 50, Ulsan 689-798, Republic of Korea. ${ }^{4}$ Department of Materials Science and Engineering, Graduate School of Green Energy Technology, Chungnam National University, Daejeon 305-764, South Korea. ${ }^{5}$ Cavendish Laboratory, JJ Thomson Avenue, Cambridge CB3 OHE, UK. ${ }^{6}$ Department of Physics and Centre for Plastic Electronics, Imperial College London, Prince Consort Road, London SW7 2AZ, UK. ${ }^{7}$ Center for Nanomaterials and Chemical Reactions, Institute for Basic Science (IBS), Department of Materials Science \& Engineering, KAIST, Daejeon 305-701, Republic of Korea. Correspondence and requests for materials should be addressed to M.H.S. (email: mhsong@unist.ac.kr).
} 


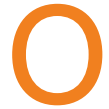
rganic/polymer-based light-emitting diodes (OLEDs/ PLEDs) have been extensively used over the past few decades for display and solid-state lighting applications because of their low cost, light weight, fast response time, large viewing angle and mechanical flexibility ${ }^{1-3}$. Nevertheless, the current state-of-the-art PLEDs still have considerable room for improvement in the device efficiency and stability needed for commercial applications.

To achieve OLEDs/PLEDs of high external quantum efficiency (EQE), two key parameters are important: a high internal quantum efficiency (IQE) including a high photoluminescence quantum efficiency (PLQE, $\eta_{\mathrm{PL}}$ ) of the emissive material, singlet formation $\left(\eta_{s}\right)$ via spin statics and a high fraction of recombination $\left(\eta_{\mathrm{re}}\right)$ of electrons and holes in the emissive layer; and a high out-coupling efficiency $\left(\eta_{\mathrm{e}}\right)$ such that a high fraction of photons escape the device. In conventionally-structured PLEDs, $\eta_{\mathrm{e}}$ is particularly poor at approximately $20 \%$ because the light generated in the emissive semiconductor is trapped and waveguided inside the OLEDs/PLEDs ${ }^{4-8}$.

Inverted-structured polymer light-emitting diodes (iPLEDs) have recently been established as a the substitute for conventional PLEDs because of the good air-stability of such devices, which use high-work-function metal for the anode and air-stable metaloxide layers for the electron- and hole-injection layers ${ }^{9-13}$. However, there are certain critical obstacles impeding the realization of highly efficient iPLEDs. In particular, the majority of the light generated in the polymeric emissive layer is fully reflected and trapped by in-plane waveguide (WG) optical modes because of the use of high-reflective-index layers such as metaloxide $\left(n_{\mathrm{MO}} \sim 1.8-2.4\right)$ as the electron-injection layer, which results in low $\eta_{\mathrm{e}}$ values for iPLEDs ${ }^{14-17}$.

Thus far, several approaches have been proposed to solve the problem of waveguiding in OLEDs/PLEDs. One method of enhancing the out-coupling efficiency is to use a high-refractiveindex glass substrate and a hemisphere microlens thereon ${ }^{16-18}$. Moreover, a Bragg diffraction grating (BDG), a low-index grid and an internal scattering structure of the organic layer have been introduced in these devices for the light extraction of the indium tin oxide (ITO)/organic WG mode ${ }^{19-24}$. However, BDGs fabricated using the electron-beam lithography ${ }^{19}$, nanoimprinting $\mathrm{g}^{20}$ and holographic methods ${ }^{21-23}$ incur the high costs and require complex techniques. In addition, it is difficult to extract at broad range of light emission using BDGs with regular periodic structures for white OLEDs because such a BDG extracts specific emission wavelengths in accordance with Bragg's law, depending on the specific grating period and angle. Even though several methods have been suggested to efficiently extract the ITO/ organic and glass/air WG modes, alternative methods are still required to achieve low costs, and simple manufacturing process and efficient light extraction for a broad range of wavelengths.

An additional challenge facing the development of iPLEDs is that a balance between the charge-carrier injection and transport from each electrode is crucial to increasing the efficiency of iPLEDs by improving the recombination of electrons and holes in the emissive layer. However, the charge injection and transport are unbalanced in iPLEDs that use ITO or fluorine-doped tin oxide (FTO) as the cathode; n-type metal oxide, such as zinc oxide $(\mathrm{ZnO})$, hafnium oxide $\left(\mathrm{HfO}_{2}\right)$ or zirconium oxide $\left(\mathrm{ZrO}_{2}\right)$, as the electron-injection/transport layer; poly $\left(9,9^{\prime}\right.$-dioctylfluorene-cobenzo-thiadiazole) (F8BT) or poly(phenylvinylene): super yellow as the emissive layer; molybdenum oxide $\left(\mathrm{MoO}_{3}\right)$ or nickel oxide $(\mathrm{NiO})$ as hole injection/transport layer and gold $(\mathrm{Au})$ as the anode. In fact, the hole injection in this type of device indicates an ohmic contact from the $\mathrm{MoO}_{3} / \mathrm{Au}$ to the highest occupied molecular orbital level of the emissive layer ${ }^{25,26}$, whereas the electroninjection rates are fairly low because of the considerable energy barrier difference between the conduction band (CB) of the n-type metal oxides and the lowest unoccupied molecular orbital (LUMO) of the emissive layer ${ }^{9-17,27-30}$. Recently, various strategies have been applied to promote electron injection and transport by controlling the interface between the $\mathrm{CB}$ of the n-type metal oxide and the LUMO of the emissive layer by using an interlayer, such as ionic liquid molecules (ILMs) ${ }^{27}$, conjugated polyelectrolyte ${ }^{28,29}$, self-assembled dipole monolayer ${ }^{15}$, caesium carbonate $\left(\mathrm{Cs}_{2} \mathrm{CO}_{3}\right)$ (ref. 13) or barium hydroxide $\left(\mathrm{Ba}(\mathrm{OH})_{2}\right)$ (ref. 16).

Here we show highly efficient iPLEDs by introducing a spontaneously formed ripple-shaped nanostructure of $\mathrm{ZnO}$ ( $\mathrm{ZnO}-\mathrm{R})$ and applying an amine-based polar solvent treatment using 2-methoxyethanol (2-ME) and ethanolamine (EA) cosolvents $(2-\mathrm{ME}+\mathrm{EA})$ to the $\mathrm{ZnO}-\mathrm{R}$. In particular, we solve the critical problems facing iPLEDs by enhancing the light extraction of the WG mode using spontaneously modified $\mathrm{ZnO}-\mathrm{R}$, by improving the recombination of balanced charges via the promotion of electron-injection and hole-blocking behaviour and by reducing exciton quenching through the application of a 2-ME + EA polar solvent treatment to the $\mathrm{ZnO}-\mathrm{R}$ for the ultimate iPLED devices.

\section{Results}

iPLEDs structure. Figure 1a,b provide illustrations of the entire device structure of the iPLEDs, including the interfacial layer and the different surfaces of the $\mathrm{ZnO}$ layers: flat $\mathrm{ZnO}(\mathrm{ZnO}-\mathrm{F})$ and $\mathrm{ZnO}-\mathrm{R}$, respectively. The insets illustrate the chemical structures of the emissive polymer, F8BT, and the interfacial layer of 2-ME and EA. The iPLEDs were fabricated via the sequential deposition of $\mathrm{ZnO}, 2-\mathrm{ME}+\mathrm{EA}, \mathrm{F} 8 \mathrm{BT}, \mathrm{MoO}_{3}$ and $\mathrm{Au}$ onto an FTO-coated glass substrate; this process is described in detail in the Methods section. Although the glass WG mode remains inside the device and therefore cannot contribute to the total light extraction, the $\mathrm{ZnO}$ /organic WG modes can be stimulated to be out-coupled by the $\mathrm{ZnO}-\mathrm{R}$.

Ripple-shaped nanostructure of ZnO. The different surface properties of each type of $\mathrm{ZnO}$, such as morphology, height, period and roughness, are determined by controlling the heating
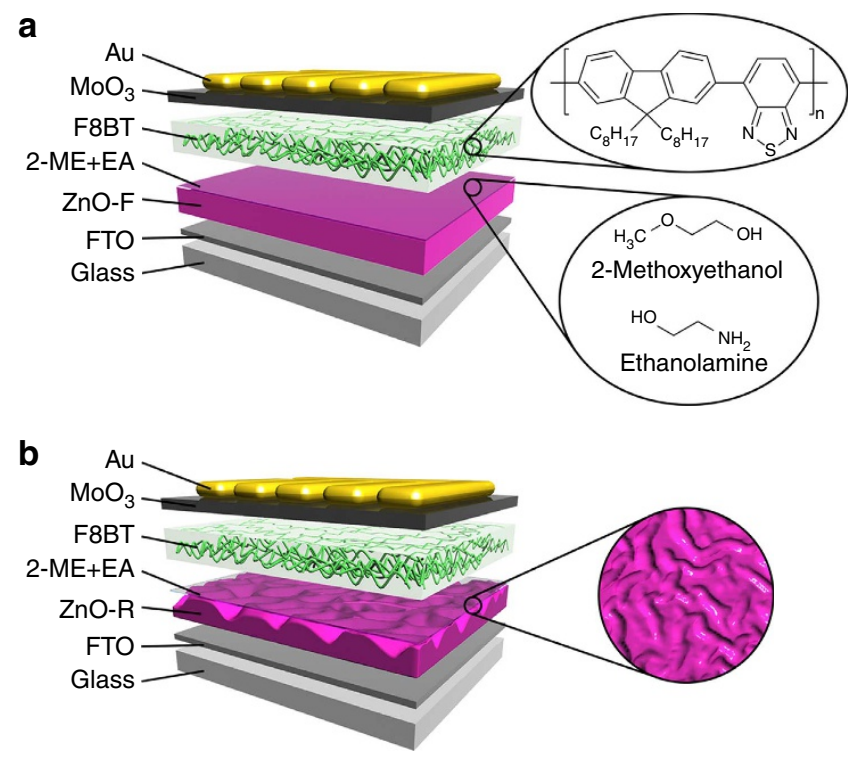

Figure 1 | Schematic illustrations of iPLED devices. The insets illustrate the chemical structures of the emissive layer, F8BT, and the interfacial layer, $2-\mathrm{ME}+\mathrm{EA}$, as well as the detailed surface structure of $\mathrm{ZnO}-\mathrm{R}$. $(\mathbf{a}, \mathbf{b})$ Device architectures of iPLEDs with (a) $\mathrm{ZnO}-\mathrm{F}$ and (b) $\mathrm{ZnO}-\mathrm{R}$. 
rate during annealing and the concentration of the $\mathrm{ZnO}$ solution $^{31-33}$. The $\mathrm{ZnO}$ ripple-shaped nanostructure was formed by the reorganization of gel particles of zinc acetate dihydrate $\left[\mathrm{Zn}\left(\mathrm{CH}_{3} \mathrm{COO}\right)_{2} 2 \mathrm{H}_{2} \mathrm{O}\right]$ during the slow drying process ${ }^{34,35}$. $\mathrm{ZnO}$ layers with a ripple-shaped nanostructure of lesser height and narrower width ( $\mathrm{ZnO}-\mathrm{R} 1)$ were developed when the spin-coated $\mathrm{ZnO}$ samples were heated to $400^{\circ} \mathrm{C}$ at a rapid heating rate $\left(20^{\circ} \mathrm{C}\right.$ per minute), whereas structures of higher height and broader width (ZnO-R2) were fabricated using a slower heating rate $\left(10^{\circ} \mathrm{C}\right.$ per minute). The preparation of the $2-\mathrm{ME}+\mathrm{EA}$ interlayer and the $\mathrm{ZnO}$ layers is described in the Methods section.

Three different types of $\mathrm{ZnO}, \mathrm{ZnO}-\mathrm{F}, \mathrm{ZnO}-\mathrm{R} 1$ and $\mathrm{ZnO}-\mathrm{R} 2$, with and without the 2-ME + EA interfacial layer were fabricated spontaneously by following the solution process using various heating rates during annealing, and the different $\mathrm{ZnO}$ types were confirmed via atomic force microscopy (AFM) in tapping mode, as shown in Fig. $2 \mathrm{a}-\mathrm{d}$. The $\mathrm{ZnO}-\mathrm{F}$ without $2-\mathrm{ME}+\mathrm{EA}$ has a root-mean-square (rms) roughness $\left(R_{\mathrm{rms}}\right)$ of $2.13 \mathrm{~nm}$, whereas the $\mathrm{ZnO}-\mathrm{F}$ with $2-\mathrm{ME}+\mathrm{EA}$ has a smoother surface with an $R_{\mathrm{rms}}$ of $1.21 \mathrm{~nm}$. In contrast, the $\mathrm{ZnO}-\mathrm{R} 1$ with $2-\mathrm{ME}+\mathrm{EA}$ has an $R_{\mathrm{rms}}$ of $3.11 \mathrm{~nm}$, a height of $\sim 30 \mathrm{~nm}$ and a period of $\sim 300 \mathrm{~nm}$ (the dominant period over a broad wavelength range), and the $\mathrm{ZnO}$ $\mathrm{R} 2$ with $2-\mathrm{ME}+\mathrm{EA}$ has an $R_{\mathrm{rms}}$ of $13.1 \mathrm{~nm}$, a height of $\sim 70 \mathrm{~nm}$,
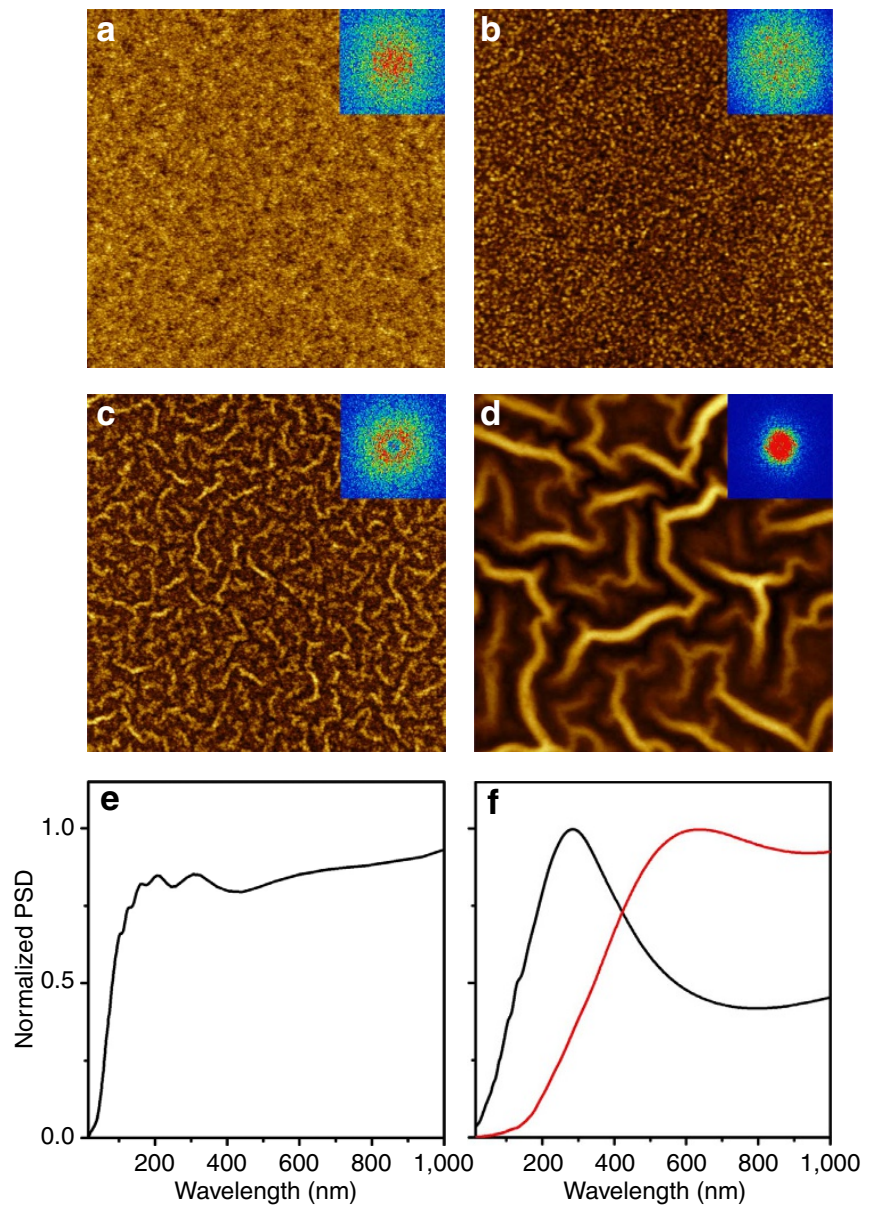

Figure 2 | AFM analysis of ZnO layers. Dimensions: $5 \mu \mathrm{m} \times 5 \mu \mathrm{m}$. (a-d) AFM images and $R_{\text {rms }}$ values of $\mathrm{ZnO}-\mathrm{F}$ layers (a) without $\left(R_{\mathrm{rms}}=2.13 \mathrm{~nm}\right)$ and (b) with the $2-\mathrm{ME}+\mathrm{EA}$ interlayer $\left(R_{\mathrm{rms}}=1.21 \mathrm{~nm}\right)$ and of (c) $\mathrm{ZnO}-\mathrm{R} 1$ $\left(R_{\mathrm{rms}}=3.11 \mathrm{~nm}\right)$ and $(\mathbf{d}) \mathrm{ZnO}-\mathrm{R} 2$ layers with the 2-ME + EA interlayer $\left(R_{\text {rms }}=13.1 \mathrm{~nm}\right)$. Insets: The FFT of each $\mathrm{ZnO}$ layer. Isotropic PSD plots from FFT analysis for (e) ZnO-F layers without the 2-ME + EA interlayer and (f) $\mathrm{ZnO}-\mathrm{R} 1$ (black) and $\mathrm{ZnO}-\mathrm{R} 2$ (red) layers with the 2-ME + EA interlayer. and a period of $\sim 600 \mathrm{~nm}$ (the dominant period over a broad wavelength range). The periodicity of the ripple-shaped nanostructure of the $\mathrm{ZnO}$ layer was analysed by using the fast Fourier transform (FFT) method. Both $\mathrm{ZnO}-\mathrm{F}$ layers regardless of the 2-ME + EA layer have no characteristic FFT patterns, indicating the absence of any periodic structure. In the case of the $\mathrm{ZnO}-\mathrm{R} 1$ and $\mathrm{ZnO}-\mathrm{R} 2$ with the interfacial layer, their FFT results exhibit ring-like patterns that represent a ripple structure with a random orientation and a spatial period. Furthermore, the power spectral density calculated from the FFT indicates that there is a significant difference in the periodicities of the ripple structures of $\mathrm{ZnO}-\mathrm{R} 1$ and $\mathrm{ZnO}-\mathrm{R} 2$ with a wide distribution, as shown in Fig. 2f, while no characteristic periodicity is observed in the $\mathrm{ZnO}$ F layer, as shown in Fig. 2e. A spontaneously formed, randomly oriented $\mathrm{ZnO}-\mathrm{R}$ layer with a wide period distribution can potentially be used as the out-coupler for the WG light to extract a broad range of emission wavelengths, regardless of direction.

iPLED performance. The device characterisations of the iPLEDs with differently structured $\mathrm{ZnO}$ layers ( $\mathrm{ZnO}-\mathrm{F}, \mathrm{ZnO}-\mathrm{R} 1$ and $\mathrm{ZnO}-\mathrm{R} 2$ ) and interfacial layers are presented in Fig. 3 and Table 1; the presented data include (a) current density versus voltage $(J-V)$, (b) luminance versus applied voltage $(L-V)$, (c) luminous efficiency versus current density $(L E-J)$, (d) power efficiency versus current density $(P E-J)$, (e) EQE versus current density $(E Q E-J)$ and (f) normalized electroluminescence (EL) spectra. The efficiencies of the iPLEDs for the three different types of $\mathrm{ZnO}$ layers include $L E$ s of 11.7 ( $\mathrm{ZnO}-\mathrm{F} / 2-\mathrm{ME}+\mathrm{EA}), 14.8$ (ZnO-R1/2-ME + EA) and $12.5 \mathrm{~cd} \mathrm{~A}^{-1}(\mathrm{ZnO}-\mathrm{R} 2 / 2-\mathrm{ME}+\mathrm{EA})$, PEs of $4.49,5.81$ and $4.93 \mathrm{~lm} \mathrm{~W}^{-1}$, and EQEs of $3.45,4.36$ and $3.68 \%$, respectively. In particular, the device efficiencies with $\mathrm{ZnO}-\mathrm{R} 1 / 2-\mathrm{ME}+\mathrm{EA}$ are higher than those for $\mathrm{ZnO}-\mathrm{F} / 2-\mathrm{ME}+$ EA by approximately $25 \%$ for $L E, 30 \%$ for $P E$ and $25 \%$ for $E Q E$ because $\mathrm{ZnO}-\mathrm{R} 1 / 2-\mathrm{ME}+\mathrm{EA}$ can extract the $\mathrm{ZnO} /$ organic WG mode from inside the device structure (Supplementary Fig. 1). To confirm the enhancement of the out-coupling efficiency achieved using $\mathrm{ZnO}-\mathrm{R}$, an angular-dependence measurement was conducted using an angular stage to measure the normalized EL spectra at various angles from $0^{\circ}$ to $80^{\circ}$. In this study, strongly waveguided edge emission, which can occur at around $90^{\circ}$ in the iPLEDs using high refractive index of $\mathrm{ZnO}-\mathrm{F}$, is ignored because this edge emission is useless for display applications. Interestingly, all emission patterns of the iPLEDs with $\mathrm{ZnO}-\mathrm{F}, \mathrm{ZnO}-\mathrm{R} 1$ and $\mathrm{ZnO}-\mathrm{R} 2$ are similar to that of a Lambertian pattern and the integrated EL intensities are enhanced by approximately $26 \%$ (ZnO-R1) and $11 \%(\mathrm{ZnO}-\mathrm{R} 2)$ with respect to that of iPLED using $\mathrm{ZnO}-\mathrm{F}$ (reference) because of the out-coupling effect. The use of high-reflective-index layer for the $\mathrm{ZnO}$ layer confines the WG modes within the interface of the $\mathrm{ZnO}$ and the emissive layers and the introduction of $\mathrm{ZnO}-\mathrm{R}$ improves the out-coupling of the light trapped within the devices and reduces in-plane WG losses. In particular, the efficiency of the iPLED with ZnO-R2 is lower than that of the iPLED with $\mathrm{ZnO}-\mathrm{R} 1$ because of the optical quenching and trapping of photons caused by the higher surface roughness of $\mathrm{ZnO}-\mathrm{R} 2$.

The efficiency of iPLEDs with $\mathrm{ZnO}-\mathrm{R}$ was further increased by the application of an amine-based solvent treatment to the $\mathrm{ZnO}$ $\mathrm{R}$. We have demonstrated that applying a polar solvent treatment to the $\mathrm{ZnO}$ surface reduces the contact barrier between the active polymer and the $\mathrm{ZnO}$ layer because of the interfacial negative dipole effect, which is created spontaneously by the absorption of the amine $\left(\mathrm{NH}_{2}\right)$ and hydroxyl $(\mathrm{OH})$ groups of EA on $\mathrm{ZnO}-\mathrm{R}$, enhancing the electron extraction by suppression of recombination of the electron and hole carriers ${ }^{31}$. The interfacial negative dipolar polarization that the nitrogen atoms and $\mathrm{OH}$ groups with 

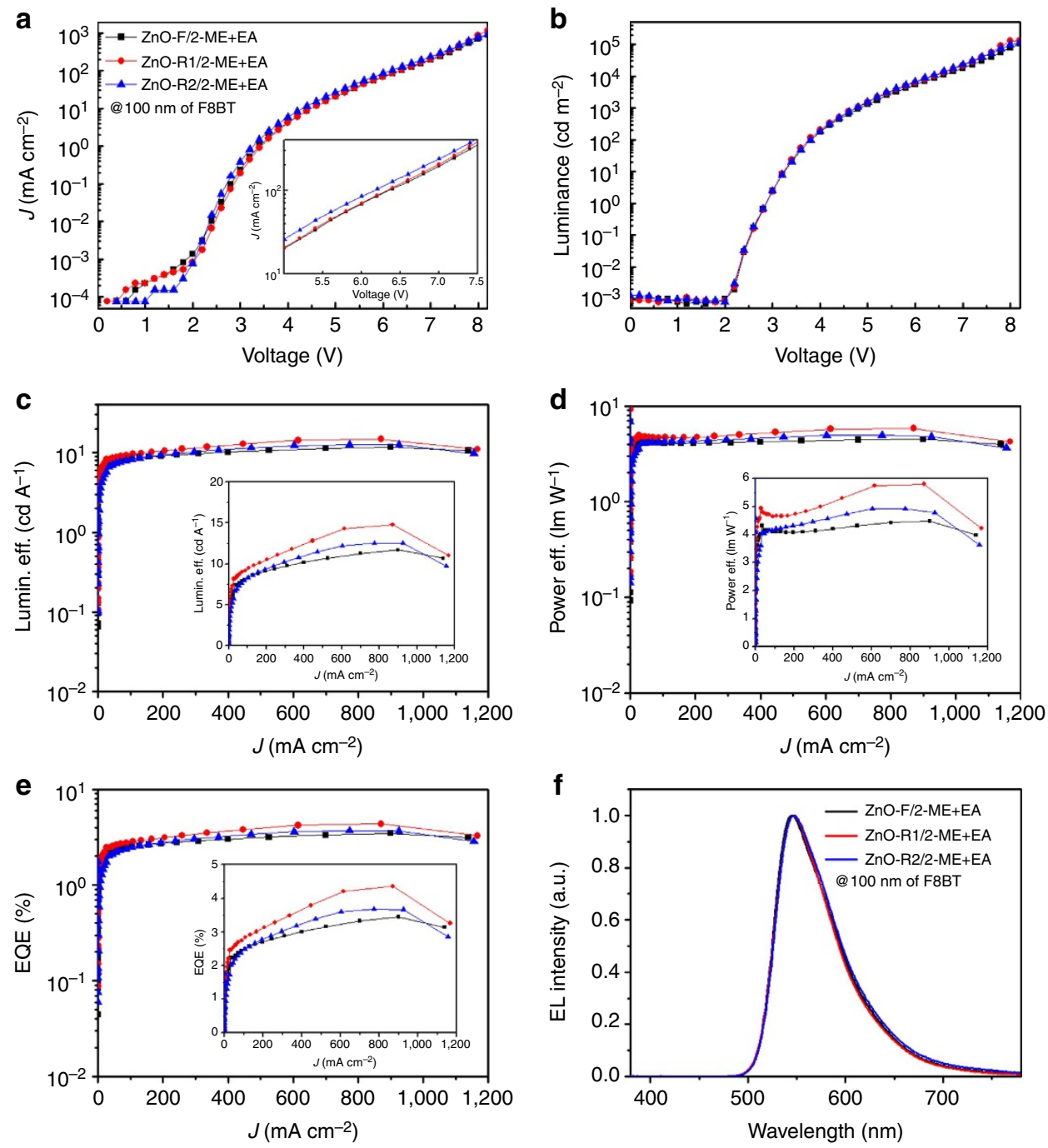

Figure 3 | Performances of iPLEDs with 2-ME + EA and differently structured ZnO layers. (a) Current density versus voltage ( $J-V)$ characteristics, (b) luminance versus applied voltage $\left(L-V, c d m^{-2}\right)$, (c) luminous efficiency (lumin. eff.) versus current density $\left(L E-J\right.$, cd $\left.A^{-1}\right)$, (d) power efficiency versus current density $\left(P E-J, I \mathrm{~m} \mathrm{~W}^{-1}\right)$, (e) EQE versus current density (EQE-J, \%) and (f) normalized electroluminescence (EL) spectra of the iPLEDs. The insets of c-e show $L E-J, P E-J$ and $E Q E-J$ on a linear-linear scale.

\begin{tabular}{|c|c|c|c|c|c|}
\hline Device configuration & 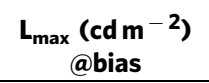 & $\begin{array}{c}\mathbf{L E}_{\max }\left(\mathrm{cd} \mathrm{A}^{-1}\right) \\
@ \text { bias }\end{array}$ & $\begin{array}{c}\mathrm{PE}_{\max }\left(\operatorname{Im} \mathbf{W}^{-1}\right) \\
\text { @bias }\end{array}$ & $\begin{array}{c}\mathrm{EQE}_{\max }(\%) \\
\text { @bias }\end{array}$ & $\begin{array}{c}\text { Turn-on } \\
\text { voltage (V) }\end{array}$ \\
\hline $\mathrm{FTO} / \mathrm{ZnO}-\mathrm{F} / 2-\mathrm{ME}+\mathrm{EA} / \mathrm{F} 8 \mathrm{BT}(100 \mathrm{~nm}) / \mathrm{MoO}_{3} / \mathrm{Au}$ & $105,400(8.2 \mathrm{~V})$ & $11.7(8.2 \mathrm{~V})$ & $4.49(8.2 \mathrm{~V})$ & $3.45(8.2 \mathrm{~V})$ & 2.0 \\
\hline $\mathrm{FTO} / \mathrm{ZnO}-\mathrm{R} 1 / 2-\mathrm{ME}+\mathrm{EA} / \mathrm{F} 8 \mathrm{BT}(100 \mathrm{~nm}) / \mathrm{MoO}_{3} / \mathrm{Au}$ & $128,900(8.2 \mathrm{~V})$ & $14.8(8.0 \mathrm{~V})$ & $5.81(8.0 \mathrm{~V})$ & $4.36(8.0 \mathrm{~V})$ & 2.0 \\
\hline $\mathrm{FTO} / \mathrm{ZnO}-\mathrm{R} 2 / 2-\mathrm{ME}+\mathrm{EA} / \mathrm{F} 8 \mathrm{BT}(100 \mathrm{~nm}) / \mathrm{MoO}_{3} / \mathrm{Au}$ & $115,800(8.2 \mathrm{~V})$ & $12.5(8.0 \mathrm{~V})$ & $4.93(8.0 \mathrm{~V})$ & $3.68(8.0 \mathrm{~V})$ & 2.0 \\
\hline
\end{tabular}

EA, ethanolamine; EQE, external quantum efficiency; FTO, fluorine-doped tin oxide; iPLED, inverted-structured polymer light-emitting diode; L, luminance; LE, luminous efficiency; ME, methoxyethanol; EA, ethanolamine; EQE,
$\mathrm{PE}$, power eddiciency.

higher electron-negativity existed near the $\mathrm{ZnO}-\mathrm{R}$ surface while aliphatic groups $\left(-\mathrm{CH}_{2} \mathrm{CH}_{2^{-}}\right)$with lower electron-negativity existed upward was confirmed by X-ray photoelectron spectroscopy, contact angle and ultraviolet photoelectron spectroscopy measurement. More detailed contents regarding the surface electronic structure by $2-\mathrm{ME}+\mathrm{EA}$ treatment are shown inref. 31. To support the reduction of the electroninjection barrier between the active polymer layer and the $\mathrm{ZnO}$ layer and the promotion of electron injection and transport by the interfacial negative dipole effect, the current densities of the electron-only devices (FTO/ZnO-R1/F8BT/LiF/Al) with and without 2-ME + EA were measured (Supplementary Fig. 2). The current density of electron-only device with $2-\mathrm{ME}+\mathrm{EA}$ is much larger than that of reference device without 2-ME+EA. This result clearly demonstrates that the electron injection and transport in the devices treated with $2-\mathrm{ME}+\mathrm{EA}$ are enhanced due to the negative dipolar polarization effect. The iPLEDs with $2-\mathrm{ME}+\mathrm{EA}$ exhibit low current densities $(J)$ because of a reduced leakage current and significantly enhanced device efficiencies because of the enhanced recombination of electrons and holes 
inside the emissive layer (see Supplementary Fig. 4a). Thus, the iPLEDs with $\mathrm{ZnO}-\mathrm{R} 1$ and 2-ME + EA has a high luminance of $100,500 \mathrm{~cd} \mathrm{~m}^{-2}$, an $L E$ of $17.3 \mathrm{~cd} \mathrm{~A}^{-1}$, a $P E$ of $6.60 \mathrm{~lm} \mathrm{~W}^{-1}$ and an EQE of $4.91 \%$, which are approximately 11-fold, 14-fold, 16-fold and 14-fold higher, respectively, than the corresponding values for the iPLED with the same $\mathrm{ZnO}$ structure without $2-\mathrm{ME}+\mathrm{EA}$, as shown in Supplementary Fig. 4 and Supplementary Table 1.

Figure 4 provides the exciton lifetimes of F8BT on various $\mathrm{ZnO}$ layers with and without the 2-ME + EA layer determined via time-correlated single photon counting (TCSPC). The exciton lifetimes of F8BT on $\mathrm{ZnO}-\mathrm{F}, \mathrm{ZnO}-\mathrm{R} 1$ and $\mathrm{ZnO}-\mathrm{R} 2$ are 1.44, 1.41 and $1.28 \mathrm{~ns}$ at $540 \mathrm{~nm}$, respectively. The exciton lifetime of F8BT on $\mathrm{ZnO}-\mathrm{R} 2$ is significantly shorter than that on $\mathrm{ZnO}-\mathrm{F}$ because of the high surface roughness, which causes considerable exciton quenching. However, the exciton lifetime of F8BT on $\mathrm{ZnO}-\mathrm{R} 1$ is comparable to that on $\mathrm{ZnO}-\mathrm{F}$. Moreover, the exciton lifetimes are increased by coating a $2-\mathrm{ME}+\mathrm{EA}$ interlayer onto the $\mathrm{ZnO}$ layer, which is the opposite of the results obtained when measuring exciton lifetimes for conjugated polyelectrolyte and $\mathrm{Cs}_{2} \mathrm{CO}_{3}$ interlayers on $\mathrm{ZnO}^{16,28}$; the application of the $2-\mathrm{ME}+\mathrm{EA}$ polar solvent treatment to the $\mathrm{ZnO}$ layers results in reduced exciton quenching. These results are summarized in Supplementary Table 3. Moreover, the photoluminescence (PL) spectra of $\mathrm{ZnO} /$ $\mathrm{F} 8 \mathrm{BT}$ and $\mathrm{ZnO} / 2-\mathrm{ME}+\mathrm{EA} / \mathrm{F} 8 \mathrm{BT}$ were measured to support the reduction of exciton quenching by $2-\mathrm{ME}+\mathrm{EA}$. The $\mathrm{PL}$ intensities of $\mathrm{ZnO}-\mathrm{F}$ and $\mathrm{ZnO}-\mathrm{R} 1$ with $2-\mathrm{ME}+\mathrm{EA}$ are higher than those of $\mathrm{ZnO}-\mathrm{F}$ and $\mathrm{ZnO}-\mathrm{R} 1$ without 2-ME + EA (Supplementary Fig. 3). These PL results are in agreement with the TCSPC data, which can support the reduced exciton quenching. Therefore, it is concluded that the application of a $2-\mathrm{ME}+\mathrm{EA}$ interlayer on $\mathrm{ZnO}$ is effective for enhancing the electrical and optical properties of iPLED devices, as indicated by the $J-V-L$ characteristic curves and the TCSPC and PLQE data.

Friend et al. ${ }^{2}$ have previously reported that because of the large recombination zone, optimized iPLEDs can be made to exhibit
LEs of more than $20 \mathrm{~cd} \mathrm{~A}^{-1}$ by controlling the width of the recombination zone with an approximately $1-\mu \mathrm{m}$-thick F8BT layer ${ }^{16,36}$. Here, we optimized the efficiencies of the iPLEDs by using emissive layer of different thicknesses ranging from 100 to $1,200 \mathrm{~nm}$ and $\mathrm{ZnO}-\mathrm{R} 1$ to which the 2-ME+EA co-solvent treatment had been applied. As the thickness of the F8BT emissive layers was increased, the $L E, P E$ and $E Q E$ improved although the luminance decreased. Among the tested devices, the iPLED with 1,200-nm-thick F8BT exhibits the highest values, with a luminance of $53,400 \mathrm{~cd} \mathrm{~m}^{-2}$, an $L E$ of $61.6 \mathrm{~cd} \mathrm{~A}^{-1}$, a $P E$ of $19.4 \mathrm{~lm} \mathrm{~W} \mathrm{~W}^{-1}$ and an $E Q E$ of $17.8 \%$, as shown in Fig. 5 and Table 2. The device efficiencies with 1,200-nm-thick F8BT and $\mathrm{ZnO}-\mathrm{R} 1$ treated $2-\mathrm{ME}+\mathrm{EA}$ are much higher than those with 1,200-nm-thick F8BT and $\mathrm{ZnO}-\mathrm{F}$ treated 2-ME+EA (Supplementary Fig. 5 and Supplementary Table 2). It should be highlighted that the $E Q E$ value of approximately $18 \%$ is the record high value thus far presented for fluorescent PLED devices that contain a single polymer emissive layer (Supplementary Table 4). Moreover, a further increase in device efficiency can be obtained using a high-refractive-index glass substrate and a hemisphere microlens thereon to extract the glass/air WG mode, although they were not used in this study.

If we assume that the recombination $\left(\eta_{\mathrm{re}}\right)$ of electrons and holes in the emissive layer is $100 \%$, the singlet formation $\left(\eta_{\mathrm{s}}\right)$ via spin statics is $25 \%$, the PLQE $\left(\eta_{\mathrm{PL}}\right)$ of the material is $100 \%$ and the light extraction $\left(\eta_{\mathrm{e}}\right)$ of the iPLEDs is $25 \%$, then the calculation indicates that a maximum $E Q E\left(E Q E=\eta_{\mathrm{re}} \eta_{\mathrm{s}} \eta_{\mathrm{PL}} \eta_{\mathrm{e}}\right)$ of $5 \%$ can be achieved, which is significantly lower than the maximum EQE of $17.8 \%$ observed in this experiment. Two possible explanations for such a high $E Q E$ are as follows: (i) the value of $\eta_{\mathrm{s}}$ attributable to electrical injection may be higher than $25 \%$ because of the triplet-triplet annihilation process ${ }^{37,38}$ and the fact that the singlet-formation cross-section of F8BT is greater than the triplet-formation cross-section of $\mathrm{FBBT}^{39}$ and (ii) the enhanced light extraction $\left(\eta_{\mathrm{e}}\right)$ of the iPLEDs achieved by using $\mathrm{ZnO}-\mathrm{R}$ may also contribute to the high $E Q E$ value. a

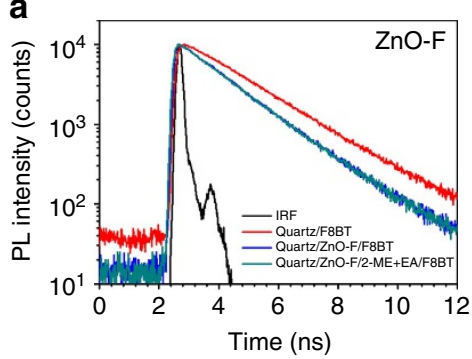

d

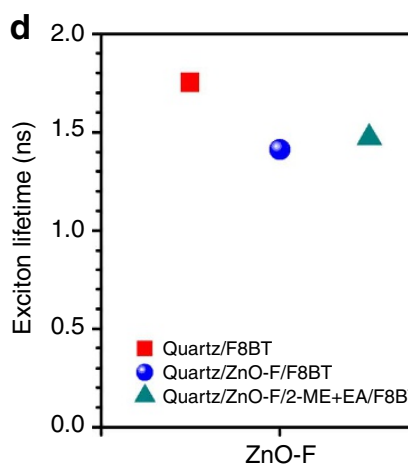

b

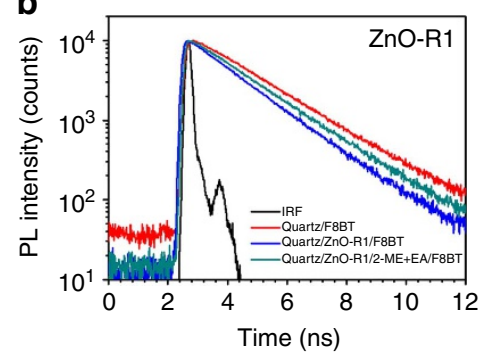

C

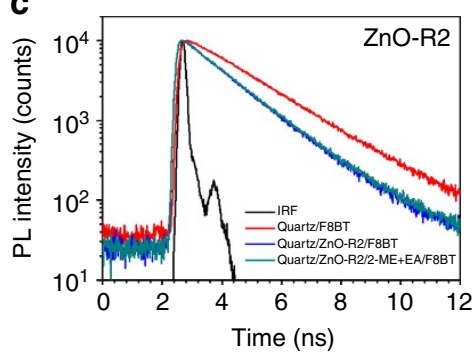

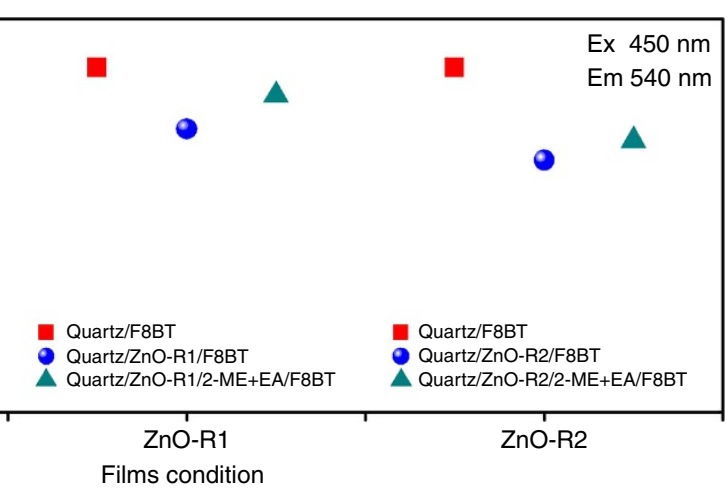

Figure 4 | Exciton lifetime. (a-c) Time-resolved PL signal of (a) Quartz/ZnO-F/F8BT, (b) Quartz/ZnO-R1/F8BT and (c) Quartz/ZnO-R2/F8BT with and without 2-ME +EA, measured via TCSPC at an excitation wavelength of $450 \mathrm{~nm}$ and an emission wavelength of $540 \mathrm{~nm}$. (d) Summary of the exciton lifetimes of F8BT on the different $\mathrm{ZnO}$ layers. 

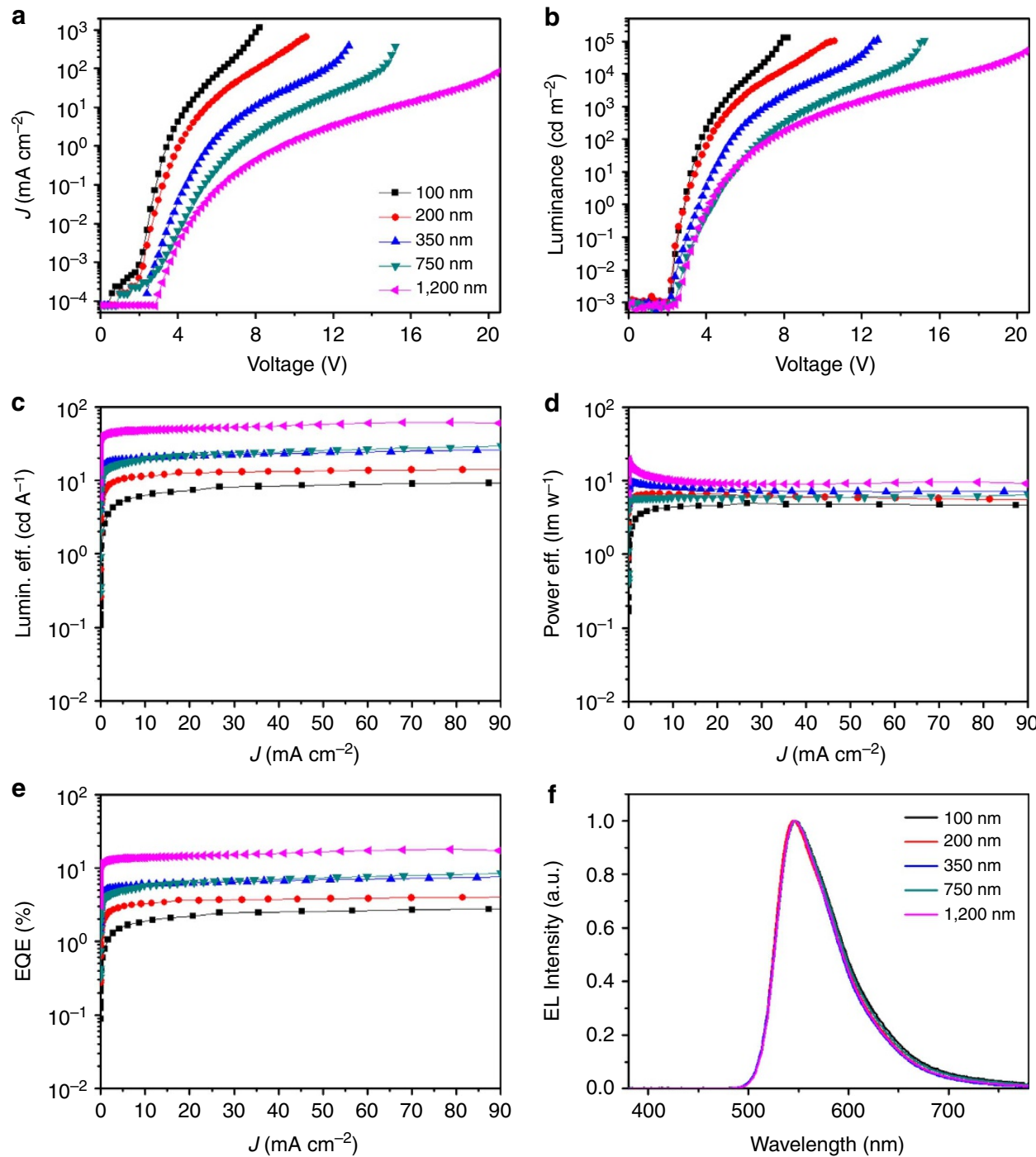

Figure 5 | Performance of iPLEDs devices using 2-ME + EA and ZnO-R1 with various thicknesses of F8BT. (a) Current density versus voltage ( $J$ - $V$ ) characteristics, (b) luminance versus applied voltage $\left(L-V, c d m^{-2}\right)$, (c) luminous efficiency (lumin. eff.) versus current density $\left(L E-J\right.$, $\left.c d A^{-1}\right),(\mathbf{d})$ power efficiency versus current density $\left(P E-J, I \mathrm{~m} \mathrm{~W}^{-1}\right),(\mathbf{e})$ EQE versus current density $(E Q E-J, \%)$ and (f) normalized electroluminescence (EL) spectra of the iPLEDs.

Table 2 | Summary of device performance for iPLEDs with ZnO-R1, 2-ME + EA and various thicknesses of F8BT.

\begin{tabular}{|c|c|c|c|c|c|}
\hline Device configuration & $\begin{array}{c}\mathbf{L}_{\max }\left(\mathbf{c d ~ m}^{-2}\right) \\
\text { @bias }\end{array}$ & $\begin{array}{c}\mathbf{L E}_{\max }\left(\mathbf{c d ~ A ^ { - 1 }}\right) \\
\text { @bias } \\
\end{array}$ & $\begin{array}{c}\mathbf{P E}_{\max }\left(\operatorname{lm} \mathbf{W}^{-1}\right) \\
@ \text { bias }\end{array}$ & $\begin{array}{c}\mathrm{EQE}_{\max }(\%) \\
\text { @bias } \\
\end{array}$ & $\begin{array}{c}\text { Turn-on } \\
\text { voltage (V) }\end{array}$ \\
\hline FTO/ZnO-R1/2-ME +EA/F8BT $(100 \mathrm{~nm}) / \mathrm{MoO}_{3} / \mathrm{Au}$ & $128,900(8.2 \mathrm{~V})$ & $14.8(8.0 \mathrm{~V})$ & $5.81(8.0 \mathrm{~V})$ & $4.36(8.0 \mathrm{~V})$ & 2.0 \\
\hline $\mathrm{FTO} / \mathrm{ZnO}-\mathrm{R} 1 / 2-\mathrm{ME}+\mathrm{EA} / \mathrm{F} 8 \mathrm{BT}(200 \mathrm{~nm}) / \mathrm{MoO}_{3} / \mathrm{Au}$ & $100,500(10.6 V)$ & $17.3(10.2 \mathrm{~V})$ & $6.60(5.2 \mathrm{~V})$ & $4.91(10.2 \mathrm{~V})$ & 2.0 \\
\hline $\mathrm{FTO} / \mathrm{ZnO}-\mathrm{R} 1 / 2-\mathrm{ME}+\mathrm{EA} / \mathrm{F} 8 \mathrm{BT}(750 \mathrm{~nm}) / \mathrm{MoO}_{3} / \mathrm{Au}$ & $101,700(15.2 \mathrm{~V})$ & $40.0(15.0 \mathrm{~V})$ & $8.38(15.0 \mathrm{~V})$ & $11.6(15.0 \mathrm{~V})$ & 2.2 \\
\hline $\mathrm{FTO} / \mathrm{ZnO}-\mathrm{R} 1 / 2-\mathrm{ME}+\mathrm{EA} / \mathrm{F} 8 \mathrm{BT}(1,200 \mathrm{~nm}) / \mathrm{MoO}_{3} / \mathrm{Au}$ & $53,400(20.6 \mathrm{~V})$ & $61.6(20.4 \mathrm{~V})$ & $19.4(4.8 \mathrm{~V})$ & $17.8(20.4 \mathrm{~V})$ & 2.6 \\
\hline
\end{tabular}

EA, ethanolamine; EQE, external quantum efficiency; FTO, fluorine-doped tin oxide; iPLED, inverted-structured polymer light-emitting diode; L, luminance; LE, luminous efficiency; ME, methoxyethanol; $\mathrm{PE}$, power eddiciency.

Finite-difference time-domain calculation. To investigate the enhanced device performance with regard to light extraction, we calculated the dispersion curves of the proposed OLED devices. We used the finite-difference time-domain method to enable the calculation of the dispersion curves of the nanostructure-incorporated devices. In this calculation, we compared the flat device $(\mathrm{ZnO}-\mathrm{F})$ to the nanostructured device $(\mathrm{ZnO}-\mathrm{R} 1)$ by assuming a uniform shape (hemi-ellipse) and pattern space $(\Lambda=300 \mathrm{~nm})$ of the $\mathrm{ZnO}$ nanostructures to simplify the random nature of the nanopatterns. Supplementary Figure 6 provides the calculated dispersion curves for the transverse-magnetic and transverseelectric modes of the $\mathrm{ZnO}-\mathrm{F}$ and $\mathrm{ZnO}-\mathrm{R} 1$ devices. Supplementary Figure $6 \mathrm{~b}, \mathrm{~d}$ clearly indicate the extraction of guided modes into the air cone when the corrugated nanostructures are 
incorporated, but no such extraction is evident in the case of the flat device (Supplementary Fig. 6a,c). Even though the exact theoretical calculation of the extraction efficiency is not available due to the random nature of the patterns and the limitation of two-dimensional simulation, the extraction efficiency and the optical loss of the iPLEDs was obtained by integrating the corresponding region in the power dissipation spectrum shown in Supplementary Fig. 6 (ref. 40). In the case of $\mathrm{ZnO}-\mathrm{F}$ and $\mathrm{ZnO}-\mathrm{R} 1$ devices, the amount of power emitted directly to air $\left(k_{x}<k_{n \text { air }=1}\right)$ is increased from 19 to $34 \%$ and the optical loss including waveguided and SPP modes $\left(k_{x}>k_{n_{-} \text {glass }=1.52}\right)$ is decreased from 35 to $26 \%$. It implies that the enhancement of extraction efficiency is about $79 \%$ for the iPLED with $\mathrm{ZnO}-\mathrm{R} 1$ compared with $\mathrm{ZnO}-\mathrm{F}$. We believe that the extraction is primarily attributable to the reduction in the in-plane wave vectors of the WG modes caused by the Bragg grating vector ${ }^{7,8}$. To clarify the higher extraction in the $\mathrm{ZnO}-\mathrm{R} 1$ device $(\Lambda=300 \mathrm{~nm})$ compared with that in the $\mathrm{ZnO}-\mathrm{R} 2$ device $(\Lambda=600 \mathrm{~nm})$, we calculated the grating period as a function of the emission wavelength, as shown in Supplementary Fig. 6e (ref. 7,8). It should be noted that the corrugation period of the $\mathrm{ZnO}-\mathrm{R} 1$ device $(\Lambda=300 \mathrm{~nm})$ is well matched with the grating period that is required to extract the WG modes for the emission wavelength $(\sim 540 \mathrm{~nm})$. These simulated results are consistent with the experimental observations (Fig. 3, Supplementary Fig. 1).

\section{Discussion}

In this article, we successfully achieve an ultimate $L E$ of $61.6 \mathrm{~cd} \mathrm{~A}^{-1}$, a $P E$ of $19.4 \mathrm{~lm} \mathrm{~W}^{-1}$ and an $E Q E$ of $17.8 \%$ in iPLEDs using a simple and effective method that relies on the nanostructure of $\mathrm{ZnO}-\mathrm{R}$ and the 2-ME + EA polar solvent treatment of the $\mathrm{ZnO}-\mathrm{R}$. Spontaneously formed $\mathrm{ZnO}-\mathrm{R}$ effectively enhances the extraction of the $\mathrm{ZnO} /$ organic mode, and this enhancement is independent of the specific grating period and polar angle because of the broad periodicity distribution and the random orientation. Moreover, modification of the interface using 2-ME $+\mathrm{EA}$ controls the energy barrier between the $\mathrm{CB}$ of the $\mathrm{ZnO}-\mathrm{R}$ and the LUMO of the emissive layer to balance the injection of charges, which results in highly efficient iPLEDs. Furthermore, our approach can be applied to white PLEDs and electrically pumped organic lasers.

\section{Methods}

ZnO-R/2-ME + EA film fabrication. A 0.75-M ZnO-R solution was synthesized by dissolving zinc acetate dehydrate $\left[\mathrm{Zn}\left(\mathrm{CH}_{3} \mathrm{COO}\right)_{2} 2 \mathrm{H}_{2} \mathrm{O}\right]$ in 2-methoxyethanol and ethanolamine co-solvents. This solution was stirred at $60^{\circ} \mathrm{C}$ for $30 \mathrm{~min}$ to yield a clear and homogeneous solution ${ }^{31-33}$. The $\mathrm{ZnO}-\mathrm{R}$ precursor solution was spincast onto cleaned FTO substrates after a 30-min UV-ozone treatment and heated to $400{ }^{\circ} \mathrm{C}$ with a heating rate of $20^{\circ} \mathrm{C}$ per minute $(\mathrm{ZnO}-\mathrm{R} 1)$ or $10^{\circ} \mathrm{C}$ per minute ( $\mathrm{ZnO}-\mathrm{R} 2)$. Subsequently, the ethanolamine/2-methoxyethanol (1:20 (vol. \%)) was spin-cast at 3,000 r.p.m. on top of the $\mathrm{ZnO}-\mathrm{R}$ layer and then dried at $140{ }^{\circ} \mathrm{C}$ for $10 \mathrm{~min}$.

AFM characterization. The surface roughnesses and morphologies of the $\mathrm{ZnO}-\mathrm{F}$, $\mathrm{ZnO}-\mathrm{R} 1$ and $\mathrm{ZnO}-\mathrm{R} 2$ films with and without the 2-ME + EA layer were measured using AFM (Veeco Co.).

iPLED cell fabrication and characterization. FTO substrates were cleaned in an ultrasonic bath using a conventional cleaning process with deionised water (DI water), acetone and isopropyl alcohol and were then dried under a stream of $\mathrm{N}_{2}$. The ZnO layers were spin-coated onto FTO substrates after a 30-min UV-ozone treatment and were then heated to $400{ }^{\circ} \mathrm{C}$ with different heating rates. Then, the $2-\mathrm{ME}+\mathrm{EA}$ co-solvent was spin-cast on top of the $\mathrm{ZnO}$ layers and dried at $140^{\circ} \mathrm{C}$ for 10 min under ambient atmosphere. The emissive layer of F8BT (Cambridge Display Technology Ltd. $\left(\mathrm{Mn}=114 \mathrm{~kg} \mathrm{~mol}^{-1}\right)$ was spin-coated from a $p$-xylene solution onto the prepared $\mathrm{ZnO}-\mathrm{R} / 2-\mathrm{ME}+\mathrm{EA}$ film and then annealed at $155^{\circ} \mathrm{C}$ for $1 \mathrm{~h}$ under nitrogen. $\mathrm{A} \mathrm{MoO}_{3}(10 \mathrm{~nm})$ and $\mathrm{Au}(100 \mathrm{~nm})$ electrode were deposited via thermal evaporation under vacuum conditions $\left(<10^{-6}\right.$ Torr $)$. The area of the device was $13.0 \mathrm{~mm}^{2}$. The $J-V-L$ characteristics and efficiencies were measured using a Keithley 2400 Source Meter and a Konica Minolta spectroradiometer (CS2000), respectively.

Time-correlated single photon counting. The exciton lifetime was measured by using the TCSPC method. The details are shown in ref 41 .

\section{References}

1. Burroughes, J. H. et al. Light-emitting-diodes based on conjugated polymers. Nature 347, 539-541 (1990).

2. Friend, R. H. et al. Electroluminescence in conjugated polymers. Nature 397, 121-128 (1999).

3. Tang, C. W. \& Vanslyke, S. A. Organic electroluminescent diodes. Appl. Phys. Lett. 51, 913-915 (1987).

4. Greenham, N. C., Friend, R. H. \& Bradley, D. D. C. Angular-dependence of the emission from a conjugated polymer light-emitting diode-implications for efficiency calculations. Adv. Mater. 6, 491-494 (1994).

5. Madigan, C. F., Lu, M. H. \& Sturm, J. C. Improvement of output coupling efficiency of organic light-emitting diodes by backside substrate modification. Appl. Phys. Lett. 76, 1650-1652 (2000).

6. Chutinan, A., Ishihara, K., Asano, T., Fujita, M. \& Noda, S. Theoretical analysis on light-extraction efficiency of organic light-emitting diodes using FDTD and mode-expansion methods. Org. Electron. 6, 3-9 (2005).

7. Koo, W. H. et al. Light extraction from organic light-emitting diodes enhanced by spontaneously formed buckles. Nat. Photonics 4, 222-226 (2010).

8. Koo, W. H. et al. Light extraction of organic light emitting diodes by defective hexagonal-close-packed array. Adv. Funct. Mater. 22, 3454-3459 (2012).

9. Morii, K. et al. Encapsulation-free hybrid organic-inorganic light-emitting diodes. Appl. Phys. Lett. 89, 183510 (2006).

10. Bolink, H. J. et al. Inverted solution processable OLEDs using a metal oxide as an electron injection contact. Adv. Funct. Mater. 18, 145-150 (2008).

11. Sessolo, M. \& Bolink, H. J. Hybrid organic-inorganic light-emitting diodes. $A d v$. Mater. 23, 1829-1845 (2011).

12. Lee, T. W., Hwang, J. \& Min, S. Y. Highly efficient hybrid inorganic-organic light-emitting diodes by using air-stable metal oxides and a thick emitting layer. ChemSusChem 3, 1021-1023 (2010).

13. Kabra, D., Song, M. H., Wenger, B., Friend, R. H. \& Snaith, H. J. High efficiency composite metal oxide-polymer electroluminescent devices: a morphological and material based investigation. Adv. Mater. 20, 3447-3452 (2008).

14. Song, M. H., Kabra, D., Wenger, B., Friend, R. H. \& Snaith, H. J. Opticallypumped lasing in hybrid organic-inorganic light-emitting diodes. Adv. Func. Mater 19, 2130-2136 (2009).

15. Park, J. S. et al. Efficient hybrid organic-inorganic light emitting diodes with self-assembled dipole molecule deposited metal oxides. Appl. Phys. Lett. 96, 243306 (2010).

16. Lu, L. P., Kabra, D. \& Friend, R. H. Barium hydroxide as an interlayer between zinc oxide and a luminescent conjugated polymer for light-emitting diodes. Adv. Funct. Mater. 22, 4165-4171 (2012).

17. Lu, L. P., Kabra, D., Johnson, K. \& Friend, R. H. Charge-carrier balance and color purity in polyfluorene polymer blends for blue light-emitting diodes. $A d v$. Funct. Mater. 22, 144-150 (2012).

18. Reineke, S. et al. White organic light-emitting diodes with fluorescent tube efficiency. Nature 459, 234-238 (2009).

19. Fujita, M. et al. Optical and electrical characteristics of organic light-emitting diodes with two-dimensional photonic crystals in organic/electrode layers. Jpn. J. Appl. Phys. 44, 3669-3677 (2005).

20. Ishihara, K. et al. Organic light-emitting diodes with photonic crystals on glass substrate fabricated by nanoimprint lithography. Appl. Phys. Lett. 90, 111114 (2007).

21. Matterson, B. J. et al. Increased efficiency and controlled light output from a microstructured light-emitting diode. Adv. Mater. 13, 123-127 (2001).

22. Ziebarth, J. M., Saafir, A. K., Fan, S. \& McGehee, M. D. Extracting light from polymer light-emitting diodes using stamped Bragg gratings. Adv. Funct. Mater. 14, 451-456 (2004).

23. Jeong, S. M. et al. Enhancement of normally directed light outcoupilng from organic light-emitting diodes using nanoimprinted low-refractive-index layer. Appl. Phys. Lett. 92, 083307 (2008).

24. Sun, Y. \& Forrest, S. R. Enhanced light out-coupling of organic light-emitting devices using embedded low-index grids. Nat. Photonics 2, 483-487 (2008).

25. Nakayama, Y. et al. Origins of improved hole-injection efficiency by the deposition of $\mathrm{MoO}_{3}$ on the polymeric semiconductor poly (dioctylfluorene-altbenzothiadiazole). Adv. Funct. Mater. 19, 3746-3752 (2009).

26. Kroger, M. et al. Role of the deep-lying electronic states of $\mathrm{MoO}_{3}$ in the enhancement of hole-injection in organic thin films. Appl. Phys. Lett. 95, 123301 (2009).

27. Lee, B. R. et al. Surface modification of metal oxide using ionic liquid molecules in hybrid organic-inorganic optoelectronic devices. J. Mater. Chem. 21, 2051-2053 (2011). 
28. Choi, H. et al. Combination of titanium oxide and a conjugated polyelectrolyte for high-performance inverted-type organic optoelectronic devices. Adv. Mater. 23, 2759-2763 (2011).

29. Lee, B. R. et al. Highly efficient red-emitting hybrid polymer light-emitting diodes via Forster resonance energy transfer based on homogeneous polymer blends with the same polyfluorene backbone. ACS Appl. Mater. Interfaces 5, 5690-5695 (2013).

30. Bolink, H. J., Coronado, E., Orozco, J. \& Sessolo, M. Efficient polymer lightemitting diode using air-stable metal oxides as electrodes. Adv. Mater. 21, 79-82 (2009).

31. Lee, B. R. et al. Amine-based polar solvent treatment for highly efficient inverted polymer solar cells. Adv. Mater. 26, 494-500 (2014).

32. Sekine, N., Chou, C. H., Kwan, W. L. \& Yang, Y. ZnO nano-ridge structure and its application in inverted polymer solar cell. Org. Electron. 10, 1473-1477 (2009).

33. Lim, D. C. et al. Spontaneous formation of nanoripples on the surface of $\mathrm{ZnO}$ thin films as hole-blocking layer of inverted organic solar cells. Sol. Energy Mater. Sol. Cells 95, 3036-3040 (2011).

34. Deegan, R. D. et al. Capillary flow as the cause of ring stains from dried liquid drops. Nature 389, 827-829 (1997).

35. Rabani, E., Reichman, D. R., Geissler, P. L. \& Brus, L. E. Drying-mediated selfassembly of nanoparticles. Nature 426, 271-274 (2003).

36. Kabra, D., Lu, L. P., Song, M. H., Snaith, H. J. \& Friend, R. H. Efficient singlelayer polymer light-emitting diodes. Adv. Mater. 22, 3194-3198 (2010).

37. Wallikewitz, B. H., Kabra, D., Gélinas, S. \& Friend, R. H. Triplet dynamics in fluorescent polymer light-emitting diodes. Phys. Rev. B 85, 045209 (2012).

38. King, S. M. et al. The contribution of triplet-triplet annihilation to the lifetime and efficiency of fluorescent polymer organic light emitting diodes. J. Appl. Phys. 109, 074502 (2011).

39. Wohlgenannt, M., Tandon, K., Mazumdar, S., Ramasesha, S. \& Vardeny, Z. V. Formation cross-sections of singlet and triplet excitons in pi-conjugated polymers. Nature 409, 494-497 (2001).

40. Wolfgang B. et al. Device efficiency of organic light-emitting diodes: progress by improved light outcoupling. Phys. Status Solidi A 210, 44-65 (2013).
41. Lee, B. R. et al. Highly efficient polymer light-emitting diodes using graphene oxide as a hole transport layer. ACS Nano 6, 2984-2991 (2012).

\section{Acknowledgements}

We thank Cambridge Display Technology (CDT), Ltd., for supplying F8BT. This study was supported by the Mid-Career Researcher Program (2012R1A2A2A06046931, 2013R1A2A2A01067144). This study was also financially supported by the KIST-UNIST partnership program (2.130400.01). S.O.K. was financially supported by Institute for Basic Science (IBS) [CA1301]. S.H.M. was supported by BK21 plus (10Z20130011057) funded by the Ministry of Education of Korea.

\section{Author contributions}

B.R.L. designed and conducted most of the experiments, analysed the data and prepared the manuscript. E.D.J. fabricated to make the ZnO-R. Y.S.N. performed the experimental angular measurement. S.H.M., K.-M.L., B.-S.K. and J.-R.J. performed the isotropic PSD plots from FFT analysis and performed the finite-difference time-domain simulation. J.S.P., R.H.F., J.-S.K. and S.O.K. assisted with the interpretation of data from the 2-ME + EA analysis and angular measurements. M.H.S. initiated the study, designed all the experiments, analysed the data and prepared the manuscript. All authors discussed and commented on the manuscript.

\section{Additional information}

Supplementary Information accompanies this paper at http://www.nature.com/ naturecommunications

Competing financial interests: The authors declare no competing financial interests.

Reprints and permission information is available online at http://npg.nature.com/ reprintsandpermissions/

How to cite this article: Lee, B. R. et al. Highly efficient inverted polymer light-emitting diodes using surface modifications of ZnO layer. Nat. Commun. 5:4840 doi: 10.1038/ ncomms5840 (2014) 